\title{
The Role of Goal Orientation and Epistemological Beliefs in Intrinsic Motivation among International Engineering Students
}

\author{
Abderrahim Benlahcene ${ }^{1}$, Tahira Anwar Lashari ${ }^{2}$, Sana Anwar Lashari ${ }^{3,4, *}$, \\ Muhammad Waleed Shehzad ${ }^{5}$
}

\begin{abstract}
${ }^{1}$ School of Education and Modern Languages, Universiti Utara Malaysia (UUM), Sintok, 06010, Malaysia ${ }^{2}$ School of Electrical Engineering and Computer Science, National University of Sciences \& Technology (NUST), Pakistan ${ }^{3}$ School of Applied Psychology, Social Work and Policy, Sintok, 06010 Universiti Utara Malaysia, Kedah, Malaysia ${ }^{4}$ Riphah Institute of Clinical \& Professional Psychology, Riphah International University, QIE Campus Lahore, Pakistan ${ }^{5}$ Department of English, Foundation University Islamabad (FUI), Islamabad, Pakistan
\end{abstract}

Received April 9, 2020; Revised December 19, 2020; Accepted January 20, 2021

\section{Cite This Paper in the following Citation Styles}

(a): [1] Abderrahim Benlahcene, Tahira Anwar Lashari, Sana Anwar Lashari, Muhammad Waleed Shehzad, "The Role of Goal Orientation and Epistemological Beliefs in Intrinsic Motivation among International Engineering Students," Universal Journal of Educational Research, Vol. 9, No. 3, pp. 683- 692, 2021. DOI: 10.13189/ujer.2021.090328.

(b): Abderrahim Benlahcene, Tahira Anwar Lashari, Sana Anwar Lashari, Muhammad Waleed Shehzad (2021). The Role of Goal Orientation and Epistemological Beliefs in Intrinsic Motivation among International Engineering Students. Universal Journal of Educational Research, 9(3), 683 - 692. DOI: 10.13189/ujer.2021.090328.

Copyright $\mathrm{O} 2021$ by authors, all rights reserved. Authors agree that this article remains permanently open access under the terms of the Creative Commons Attribution License 4.0 International License

\begin{abstract}
Many studies have examined separately the impacts of goal orientations and epistemological beliefs on intrinsic motivation; however, they have not investigated the two concepts in combination to examine their interrelationships with intrinsic motivation. Using Self-Determination theory, this study utilized a cross-sectional research design involving 338 international engineering students who were selected by multistage sampling. Data were analyzed through SPSS v.23. Results of the correlation analysis revealed a significant association between goal orientation and intrinsic motivation. However, associations with epistemological beliefs were found to be insignificant. Moreover, multiple regressions revealed that goal orientations were found to be the only and the main predictor constructs that account for variance in intrinsic motivation. The results of this research provide support for a growing body of evidence regarding the positive outcomes of goal orientation adoption among the students. The findings can be used by educational instructors to offer and establish the optimal learning environment by the inclusion of interesting and enjoyable activities, along with helping students to foster their intrinsic motivation by setting optimal and realistic goals during their academic activities in the university phase.
\end{abstract}

Keywords Goal Orientation, Epistemological Beliefs, Intrinsic Motivation, Self-determination Theory, International Engineering Students

\section{Introduction}

Engineers are some of the most challenging job positions for employers to fill. In the past twenty years, the number of graduates in engineering has decreased despite various endeavors to expand enrolments in this field (Alias, Lashari, Akasah, \& Kesot, 2014; Benlahcene, Lashari, \& Lashari, 2017). One of the greatest challenges that educators face is finding effective ways to increase the number of engineering graduates such as preventing the associated etiology, and enhancing and fully understanding the factors that empower persistence among engineering students (Hernandez et al., 2014; Esa, Padi, \& Hassan, 2015). Retention in the engineering educational curriculum does not ensure persistence into the career life of engineering (Ibrahim, DeMiranda, Lashari, \& Siller, 2017). To address this issue, researchers have suggested numerous 
variables that influence the persistence and achievement of postgraduates in engineering. Motivation has been considered as the most critical factor as argued by the researchers.

In most of the psychological studies, motivation has been viewed as an engineering phenomenon as well as being central to our research and our various behaviors. Past studies have focused on exploring the factors that describe, direct or reinforce these behaviors (Lerdpornkulrat, Koul, \& Poondej, 2016; Orsini, Binnie, \& Tricio, 2018; Saari, 2012). One of the prominent roles played by motivation in educational settings is strengthening and vitalizing students' learning and creativity, leading to more skills and knowledge to face their challenges (Ryan \& Deci, 2000b). Teachers use intrinsic motivation such as positive feedback to help students gain higher scores (Vatankhah and Tanbakooei 2014). According to Ryan and Deci (2000a), motivation can be characterized as intrinsic motivation and extrinsic motivation. Students' intrinsic motivation leads to higher levels of academic performance (Cerasoli \& Ford, 2014), high overall achievement in school activities, and conceptual learning (Gottfried, Marcoulides, Gottfried, \& Oliver, 2009). Studies have established that engaging in deep tasks, and improving the psychological well-being of the students, are direct results of intrinsic motivation (Froiland, Oros, Smith, \& Hirchert, 2012; Shernoff \& Csikszentmihalyi, 2009).

Developmental research has reported a decline in student's intrinsic motivation between the period of elementary to high school (Gottfried et al., 2009). This decline in intrinsic motivation is caused by different factors, including a weak interaction between students' developmental needs and the school settings, a low level of self-efficacy for succeeding in the study (Shehzad, Lashari, Alghorbany, \& Lashari, 2019), strong focus on performance goals, controlling and extrinsic atmosphere in the school environment, low level of challenge, and low correlation of curriculum and approach to learner's real lives (Gottfried et al., 2009).

Students can pursue their learning for either intrinsic or extrinsic reasons. Nonetheless, for intrinsic reasons, it is not only more enjoyable when a student works on his or her tasks, but there is also evidence that across grade levels, intrinsic motivation is associated positively with competence, learning engagement, and achievement, and negatively related to anxiety (Reeve, 2012). According to Vansteenkiste et al. (2008), it shows that the development of an intrinsic goal in fifth and sixth-grade children (e.g. help others) leads to more enhanced persistence and conceptual learning than providing them with an extrinsic goal. Similar results have been obtained by researchers researching the high school and college learners (Maralani, 2016).

As reported in the studies with university students in Pakistan, students with a high degree of intrinsic motivation are prone to be more interested in their learning activities, take more initiative, and attain optimal academic performance. These kinds of students were interested in the learning process and in obtaining their goals, and this was reflected in their overall consistent academic performances (Afzal, Ali, Khan, \& Hamid, 2010). However, the researchers recommended further investigation of the phenomena among university students as they are less prone to be intrinsically motivated. The context of Malaysia past studies reported that students were extrinsically motivated as compared to intrinsically motivated towards learning (Bidin, Jusoff, Aziz, Salleh, \& Tajudin, 2009; Zubairi \& Sarudin, 2009). Almost all countries around the globe face the challenge of producing the most educated and talented employees via education and training to cope with 21 st-century challenges (Kenny, 2013). Malaysia is not exempt from that global trend, and its educational system is considered as a critical millstone to achieve Malaysia's goal of being an advanced country by 2020. Consequently, it is imperative to inspect the factors that may facilitate the development of intrinsic motivation among university students.

When students enter school or university, they entertain various kinds of conceptions in their minds. For instance, they may differ in terms of how they think about learning and knowledge (epistemological beliefs). These epistemological beliefs are shown to be essential concerning students' engagement, optimal learning outcomes, and overall personal growth (Heiskanen \& Lonka, 2012). In the same vein, in psycho-education literature, there is growing recognition of the importance of learners' epistemological beliefs for various aspects of adaptive learning, such as strategy use, reasoning, academic performance, information processing, and motivation (Oschatz, 2015). For example, in the science domain, Karakolidis, Pitsia, and Emvalotis (2019) argued that students' epistemological beliefs about knowledge are highly correlated to their intrinsic motivation and science achievement. Students may use their beliefs about knowledge in a particular domain to determine the difficulties of acquiring knowledge, which in turn influences their motivation (Benlahcene, Lashari, \& Lashari, 2017; Oschatz, 2015). As a result, given that students' epistemological beliefs are focusing on the cognitive process, we can state that these beliefs could be proximal antecedents of intrinsic motivation among the students.

Social cognitive psychologists report that students' goals as a motivational factor determine their approach to be engaged in learning activities (Pintrich \& Schunk, 2002). Furthermore, learners who have more complex beliefs about knowledge are more susceptible to be intrinsically motivated during their learning and attain optimal academic performance (Oschatz, 2015). In this sense, to vitalize intrinsic motivation among the students, it might be important to establish a learning setting for them that 
includes environmental factors affecting intrinsic motivation (Lerdpornkulrat, Koul, \& Poondej, 2016). Epistemological beliefs and goal orientation share analogous characteristics, for example, both concern the issues regarding beliefs and cognition of the learners about the structures of knowledge that influence the various methods to acquire that knowledge. Accordingly, epistemological beliefs and goal orientation are combined and strengthen one another and can have more effective influences to predict intrinsic motivation (Chen \& Pajares, 2010). The present study draws on principles of goal orientation and epistemological beliefs to examine how these constructs work together to predict intrinsic motivation and whether there are differences in the levels of intrinsic motivation concerning demographic variables.

\section{Previous Studies}

\subsection{Intrinsic Motivation}

The concept of intrinsic motivation emerged in psychological science and was the main direction from the 1920s until the 1960s as a reaction to behaviorism (Ryan \& Deci, 2000a). Intrinsic motivation is defined as a type of motive to learn a diverse range of skills, seek challenges, exert efforts, adopt new abilities, and have the desire for mastery and achievement (Lai, Chan, \& Wong, 2006). When the students are more intrinsically motivated, they are more likely to attain higher scores in their learning outcomes in comparison to the students who are extrinsically motivated during their learning. Legault (2017) pointed out that the students are described as intrinsically motivated learners when they engage effectively in their learning activities because of curiosity, interest, or attaining their objectives. Intrinsic motivation is often achieved by students' taking their initiative to be engaged in learning tasks instead of being pushed by their instructors, peers, or even their parents. Furthermore, intrinsic motivation is an important factor that is associated with higher levels of students' attention, persistence, and learning abilities and efficiency (Niehaus, Rudasill, \& Adelson, 2012). Students who have high intrinsic motivation showed more perseverance and were less inclined to drop out of school (Froiland et al., 2012). During their learning process, they are more likely to use deep cognitive strategies (Lai et al., 2006). Similarly, intrinsic motivation is an essential predictor for optimal performance, persistence, and various skills among adults in the work domain and is an important tool for interest and enjoyment for adults and children, which makes this construct a crucial factor for learners' overall success and their life satisfaction in their future career (Froiland et al., 2012). Self-determination theory (SDT) considered intrinsic motivation as a developmental feature of individuals (Reeve, 2012). In this way, SDT is not worried about the reasons for intrinsic motivation but with the conditions that support or reduce it, and focuses on the ideal performance of individuals, as well as the settings that promote such performance. The above-mentioned reasons alone are enough for stakeholders in education to shift their concentration toward enhancing intrinsic motivation to enhance the optimal learning of their students.

\subsection{Goal Orientation}

Elliot, Murayama, and Pekrun (2011) defined goals orientation as a set of students' behaviors and intentions that regulate their approaches to be engaged in various tasks and learning activities. Dweck and Leggett (2000) have drawn the definition of goal orientation from the classification of two types of goals that students pursue in their tasks or learning situations. Mastery goals are task-based goals where the students seek to master new skills in respect to a specific task and enhance their level of competence for new challenges, while performance goals are where the students pursue the goals to get desired feedbacks from others about their competence or to show their competency in comparison to others such as peers. Goal orientations can be described as a set of beliefs learners possess regarding their ambitions that elucidate why the goal is an essential factor to them. For instance, if a learner wants to acquire an A grade in the class, it may be for the reason that he wants to appear superior compared to his peers or he may want to comprehend the content of the subjects. Thus goal orientations demonstrate the reasons for the students' behaviors (McCollum \& Kajs, 2007).

In recent years, goal orientation approaches have become the dominant framework for intrinsic motivation especially in the studies that have been conducted within various domains such as academic, sports, and work (Asif, 2011). Goal orientation is commonly defined as the collaboration between motivational views that denote varied styles of partaking in a task and reacting to accomplishment (Pintrich, 2000). As postulated by achievement goal theory, students have various goals when engaging in their learning and goal orientation approaches have an essential role within learners' motivational settings which in turn produce a successful educational process (Dweck \& Leggett, 2000; Elliot et al., 2000; Pintrich, 2000). For example, students with a mastery of a goal-oriented approach are more susceptible to be intrinsically motivated during their learning process (Ames, 1992). Contrariwise, performance-oriented learners are more likely to show low intrinsic motivation and avoid difficult tasks (Elliot, Murayama, \& Pekrun, 2011).

\subsection{Epistemological Beliefs}

When students encounter novel knowledge, they do not only stimulate their already known knowledge related to the topic at hand but also stimulate their beliefs regarding that knowledge (Mason, Gava, \& Boldrin, 2008). Beliefs regarding knowledge are defined as epistemological beliefs, 
and they tell us about a students' nature, source of knowledge, organization, and the justification benchmarks of their claims (Hofer, 2004). The term epistemological belief denotes an individual's opinions and queries such as: what knowledge is, how knowledge is acquired, what are the benchmarks and parameters for knowledge, and whether knowledge is an entity which is obtained externally or taught to the learner by experts in the respective disciplinary fields (Grainger, 2014).

Epistemological beliefs are deemed as a lens by which learners deduce information, set benchmarks, and choose a suitable course of action to achieve their academic objectives (e.g., Hofer \& Pintrich, 2004). Researchers have argued that learners' beliefs regarding the nature of knowledge and learning are related to their motivation, strategy usage, conceptual change, and academic accomplishment (Oschatz, 2015). In a research study on university students, Karatas and Erden (2017) found that learners' epistemological beliefs had a significant influence on their motivation, extrinsic motivation, and intrinsic motivation. There exists a theoretical as well as empirical support for the association among students' epistemological beliefs and motivation of students. For instance, it was stated that learners' competency beliefs and accomplishment values depend upon their opinions related to task challenges (Buehl \& Alexander, 2005).

\section{The Present Study}

As mentioned above, Self-determination theory (SDT) considered intrinsic motivation as a developmental feature of individuals (Ryan \& Deci, 2000b). Relying on that notion, SDT is concentering on the conditions that support or reduce motivation and focused on the ideal performance of individuals, as well as the settings that promote intrinsic motivation. The current study suggests a framework to inspect the association between psychological factors including goal orientation and epistemological beliefs which may explain the predictors of intrinsic motivation as well as demographic factors, i.e., level of the study, age, and gender.

Founded upon the social-cognitive model, motivation is an active and multidimensional phenomenon that elucidates why and how learners are involved in their learning practices. All the educational institutions ought to develop and escalate the levels of intrinsic motivation among their teachers and students (Pintrich \& Schunk, 2002). After the development of the aforementioned model, a substantial amount of research has been directed towards investigating intrinsic motivation from numerous perspectives (Saari, 2012).

Elliot, Murayama, and Pekrun (2011) defined goals orientation as the reason for a person's quests and interests. Previous literature has indicated that intrinsic motivation and goal orientation are significant predictors of educational learning and accomplishments of learners (Linnenbrink \& Pintrich, 2002). Therefore, in the existing study, we assume that goal orientation is a substantial predictor of intrinsic motivation. Initially, two kinds of goals were identified by the theorists, i.e., performance goals and mastery goals (Asif, 2011). However, in an educational context, the kinds of educational goals set by the learners are considered as one of the most essential variables within motivational research settings. Recent research has suspected the maladaptive portrayal of performance goal orientation (Lerdpornkulrat, Koul, \& Poondej, 2016). They indicated that some characteristics of performance goal orientation, e.g., an aspiration towards displaying high degrees of capabilities, can be positively related to intrinsic motivation. These contradictory viewpoints regarding the association of goal orientation and intrinsic motivation emphasize the necessity to carry out more studies to investigate the connection between the aforementioned two variables and establish which particular kind of goal orientation is more efficient for amplifying intrinsic motivation for students' learning.

On the contrary, previous studies related to student learning and motivation indicated that the recognition of the significance of learners' epistemological beliefs is growing (Hofer, 2001; Schommer-Aikins, 2004). Previous literature regarding Asian learners revealed a substantial association between epistemological beliefs and crucial features of learning, i.e., learning methods, learning motivation, studying, and usage of technology (Del Rosario \& Bernardo, 2012). Besides, few studies have concentrated on how learners' epistemological beliefs are related to different kinds of motivational variables, i.e., self-efficacy, intrinsic motivation, and goal orientation (Del Rosario \& Bernardo, 2012). However, research is scarce regarding the relationship between epistemological beliefs and intrinsic motivation, even though intrinsic motivation has long been deemed as a fundamental predictor of effective learning outcomes (Buehl \& Alexander, 2005; Del Rosario \& Bernardo, 2012; Şen, Yilmaz, \& Yurdugul, 2014). In this study, we presume that epistemological beliefs are a substantial predictor of intrinsic motivation.

Though previous studies have separately investigated the impact of goal orientations (Asif, 2011; Gao, Podlog, \& Harrison, 2012; Goudas, Biddle, \& Fox, 1994) and epistemological beliefs (Buehl \& Alexander, 2005; Del Rosario \& Bernardo, 2012; Şen et al., 2014), they have never merged them and investigated the association between epistemological beliefs, intrinsic motivation, and goal orientation.

Based on the association among the aforementioned variables, we insinuate a framework that can effectively explain the most variance in intrinsic motivation (refer to Figure 1). Thus, the following hypotheses have been generated: 
1. There is a significant association between goal orientation, epistemological beliefs, and intrinsic motivation.

2. There is a significant difference between genders with intrinsic motivation.

3. Goal orientation and epistemological beliefs predict intrinsic motivation.

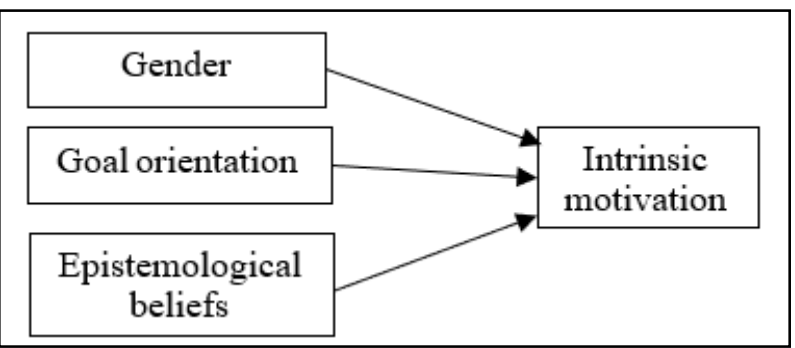

Figure 1. Conceptual Framework

\section{Materials and Methods}

\subsection{Research Design}

The present study utilized a cross-sectional research design in which data are collected from a group of subjects at one particular point in time (Turner, 2013).

\subsection{Participants}

Participants were selected from a Northern public university of Malaysia. The total population of undergraduate students was 28,025. To obtain a representative sample size, the researchers used stratified random sampling i.e. the process of segregation or stratification, followed by a random choice of subjects from each stratum (Sekaran, 2010). The stratified sampling divides the population into groups known as strata and the individual in each group are known as a stratum. Stratified sampling divides the population into groups (strata), whereby a simple random sample from each group (stratum) is taken, and data are collected from each sampling unit that is randomly sampled from each group (Ahmed, 2009) as shown in Table 1 below. Moreover, Morgan and Krejcie table was used to determine the sample size which indicates 338 as the representative Morgan and Krejcie sample. Hence, a sample of 338 international engineering students was collected using a simple random sampling technique. The participants comprised 132 females (39\%) and 206 males $(61 \%)$.

Table 1. Stratified Sample for the study

\begin{tabular}{|c|c|c|c|}
\hline Population & $\begin{array}{c}\text { Groups } \\
\text { (Strata) }\end{array}$ & Simple Random & Sample \\
\hline $\begin{array}{c}\text { All undergraduate } \\
\text { students in the } \\
\text { selected public } \\
\text { university in north }\end{array}$ & $\begin{array}{c}3 \\
\text { Academic } \\
\text { colleges }\end{array}$ & $\begin{array}{c}\text { All undergraduate } \\
\text { students from three } \\
\text { academic schools. }\end{array}$ & 338 \\
\hline
\end{tabular}

\subsection{Measures}

Demographic information of the participants such as gender, age, semester, program of study was collected through demographic information profile. However, goal orientation, Epistemological Beliefs, and Intrinsic Motivation were gathered using standardised tools. The details of which is provided are as below

\subsubsection{Goal Orientation}

A personal goal orientation from PALS was used in this study (Midgley, Carol Maehr, Martin Hruda, Lyudmila, Eric Anderman, Lynely Freeman, Kimberely \& Urdan, 2000) which consisted of 14 items that measure two dimensions including learning goals (5 items) and performance goals ( 9 items). Items of learning and performance goals were assessed on a Likert-type five points ranging from 1- strongly disagree to 5 - strongly agree. Midgley et al. (2000) reported that the coefficient alpha for the learning goal orientation was .85 while the performance goal orientation scale showed that the coefficient alpha was 89 .

\subsubsection{Epistemological Beliefs}

Student's epistemological beliefs were assessed by using Schraw's Epistemic Belief Inventory (EBI) (Schraw, Bendixen, \& Dunkle, 2002). The EBI is based on Schommer- Aikins' epistemological belief system theory and the Epistemological Belief Questionnaire. The EBI is shorter than the Epistemological Beliefs Questionnaire. Schraw et al. (2002) reported test-retest reliability, $r=0.68$, for five scales of EBI. This correlated the overall epistemological beliefs score with a reading comprehension test to evaluate EBI's predictive validity. Cronbach's alpha was 0.83 (as cited in Kennell, 2006).

The EBI consisted of 28 items and measured five epistemological beliefs which are: omniscient authority, certain knowledge, quick learning, simple knowledge, and innate ability. The questionnaire used a five point-Likert scale, ranging from 1- strongly disagree to 5- strongly agree. 18 items were written as naive statements and the other 10 were written as sophisticated statements (Kennell, 2006). The purpose of this study is to examine the relationship between general epistemological beliefs with intrinsic motivation and not based on specific beliefs related to certain subjects. Therefore this study chose 18 naive statements to measure students' epistemological beliefs at the faculty of education in UUM (as cited in Kennell, 2006).

\subsubsection{Intrinsic Motivation}

The Intrinsic Motivation Inventory (IMI) was used in this study to measure students' intrinsic motivation. The current study used this instrument because the Intrinsic Motivation Inventory is designed for college students, and thus may not be appropriate for secondary students (Phillips, 2005). This consisted of 22 items, which included 
four subscales: perceived competence (5 items), perceived choice (5 items), pressure/tension (5 items), and interest/enjoyment ( 7 items). The 22 items were assessed on a Likert-type five points ranging from 1- strongly disagree to 5- strongly agree. Although the general survey is known as the Intrinsic Motivation Inventory, it is only the interest/enjoyment subscale that measures intrinsic motivation (Self-Determination theory: Questionnaire, 2007, as cited in Asif, 2011).

As mentioned above, the interest/enjoyment subscale is considered the self-report measure of intrinsic motivation. Hence, in the present study, just the interest/enjoyment of subscale items from the 22-item IMI version was used to measure intrinsic motivation. The reliability of the interest/enjoyment subscale ( 7 items) was found to be 0.85 and those items are designed to measure the levels of interest and enjoyment among the students during their learning activities (Asif, 2011).

\section{Findings}

\subsection{Preliminary Analysis}

The researchers examined preliminary data screening test to recognize any possible violations of the multivariate assumptions before applying multivariate data analysis (Hair, Money, Samouel, \& Page, 2003) which includes (1) missing value analysis, and (2) valuation of outliers ( Jnr, Money, Samouel, \& Page, 2007).

\subsubsection{Missing Value Analysis}

Missing data were identified using Missing Value Analysis (MVA) which was found to be $2.4 \%$ of values across all scales (Tabachnick \& Fidell, 2007), substituted by means replacement if the missing data are less than $10 \%$. IMS reproduces dataset as accurately as other imputation methods (e.g. multiple imputations) across various missing patterns (Tabachnick \& Fidell, 2007).

\subsubsection{Outliers}

Outliers are identified as the existence of outliers in the data points that can extremely misrepresent results by giving unpredictable outcomes (Osborne \& Overbay, 2004). Multivariate outliers were identified by employing Mahalanobis distance. Nine multivariate outliers (i.e., 14, $22,39,41,60,112,250,265$, and 330) were identified and then removed from the dataset because they could influence the precision of the technique of data analysis. Hence, a total of 329 samples were used to run the analysis.

\subsection{Primary Analysis}

\subsubsection{Descriptive analysis}

The demographic profile for the 329 respondents was gathered to provide a clear understanding of the distribution of the respondents in terms of gender, and the number of semesters. These properties were included to give the demographic profile information on the sample. Table 2 explains the descriptive statistics demographic profile for each item in this study.

Table 2. Summary of Demographic Profile

\begin{tabular}{|c|c|c|}
\hline Demographics & Frequency & Percentage \\
\hline Gender & & \\
\hline Male & 132 & 40 \\
\hline Female & 197 & 60 \\
\hline Number of semesters & & \\
\hline First & 75 & 23 \\
\hline Second & 65 & 20 \\
\hline Third & 55 & 17 \\
\hline Fourth & 83 & 25 \\
\hline Five or more & 51 & 15 \\
\hline
\end{tabular}

\subsubsection{Hypothesis testing}

Correlation analysis was run to test the relationship among the study variables. Pearson's correlation analysis explains the relationship between independent and dependent variables as low, moderate, or high based on the value ranging between +1 and -1 .

Table 3. Correlation among study variables

\begin{tabular}{|c|c|c|c|}
\hline Variables & GO & EB & IM \\
\hline Goal orientation (GO) & 1 & & \\
\hline Epistemological beliefs (EB) & $\mathbf{. 1 8}$ & 1 & \\
\hline Intrinsic motivation (IM) & $.36^{* *}$ & .08 & 1 \\
\hline
\end{tabular}

**. Correlation is significant at the 0.01 level (2-tailed).

\subsubsection{Independent sample t-test}

To test the second research question independent sample, t-test was performed to access the difference between genders on intrinsic motivation. The results are presented in Table 4.

Table 4. Independent Sample t-test for intrinsic motivation

\begin{tabular}{|c|c|c|c|c|}
\hline Variable & \multicolumn{2}{|c|}{$\begin{array}{c}\text { Levene's Test for } \\
\text { Equality of Variances }\end{array}$} & \multicolumn{2}{c|}{ Male Female } \\
\hline Intrinsic motivation & $\mathrm{F}$ & Sig. & $\begin{array}{c}\text { Mean } \\
\text { SD }\end{array}$ & $\begin{array}{c}\text { Mean } \\
\text { SD }\end{array}$ \\
\hline $\begin{array}{c}\text { Equal variances } \\
\text { assumed }\end{array}$ & .14 & .70 & 52.85 & 54.41 \\
17.82 & 18.92 \\
\hline $\begin{array}{c}\text { Equal variances not } \\
\text { assumed }\end{array}$ & & & & \\
\hline
\end{tabular}

The assumption of homogeneity of variance was assessed by the Levene test, $F=.14, p=.70$; this indicated no significant violation of the equal variances assumption; therefore, a t-test was used. The mean difference between females $(\mathrm{M}=54.41, \mathrm{SD}=18.92)$ was higher than males $(\mathrm{M}=52.85, \mathrm{SD}=17.82)$.

\subsubsection{Multiple Regression Analysis}

A standard multiple regression analysis was conducted to evaluate how well goal orientation and epistemological 
beliefs scores predicted intrinsic motivation. The linear combination of goal orientation and epistemological beliefs scores was significantly related to intrinsic motivation (as shown in table 5 below), $\mathrm{F}((2,98)=7.411$, $\mathrm{p}<.001)$. The multiple correlation coefficient was .36 , indicating that approximately $13 \%$ of the variance of the intrinsic motivation can be accounted for by the linear combination of goal orientation and epistemological beliefs scores.

Table 5. Model summary

\begin{tabular}{|cccc|}
\hline $\begin{array}{c}\text { Model } \\
\text { Std. Error of the Estimate }\end{array}$ & Adjusted R Square \\
\hline 1 & $.362^{\mathrm{a}}$ & .13 & .11 \\
2.14 & & & \\
\hline
\end{tabular}

a. Predictors: (Constant), goal orientation, epistemological beliefs.

b. Dependent Variable: intrinsic motivation.

\begin{tabular}{|c|c|c|c|c|c|}
\hline & \multicolumn{2}{|c|}{$\begin{array}{c}\text { Unstandardized } \\
\text { Coefficients }\end{array}$} & \multicolumn{3}{c|}{$\begin{array}{c}\text { Standardized } \\
\text { Coefficients }\end{array}$} \\
\hline Model & $\mathrm{B}$ & $\begin{array}{c}\text { Std. } \\
\text { Error }\end{array}$ & Beta & $\mathrm{t}$ & Sig. \\
\hline 1 (Constant) & & 8.259 & 2.209 & 3.739 & .000 \\
\hline Goal orientation & .436 & .116 & 359 & 3.750 & .000 \\
\hline $\begin{array}{c}\text { Epistemological } \\
\text { beliefs }\end{array}$ & .006 & .031 & .017 & .181 & .857 \\
\hline
\end{tabular}

a. Dependent Variable: intrinsic motivation

In this study, goal orientation is the predictor variable that has the greatest influence on intrinsic motivation variance because the findings of multiple regressions demonstrated that goal orientation has a higher significant beta coefficient of .35 . This result indicates that intrinsic motivation increases by $35 \%$ for every one percent increase in goal orientation. Additionally, the findings demonstrated that the correlation of epistemological beliefs and intrinsic motivation was not significant and the epistemological beliefs variable failed to enter the equation as the predictor of intrinsic motivation, as indicated by the non-significant $\mathrm{t}$-value $(\mathrm{p}>.05)$.

\section{Discussion and Conclusions}

In a nutshell, the findings of this study indicate that goal orientation and intrinsic motivation are significantly associated with one another. The present result endorses the hypothesis that the level of intrinsic motivation increases with the increase in goal orientation. Past literature related to learners' goal orientation chiefly examined the association between goal orientation and intrinsic motivation. The findings indicated that goal orientation was responsible for elevating learners' intrinsic motivation and enjoyment while learning (Heintz Jr \& Steele-Johnson, 2004; Lerdpornkulrat, Koul, \& Poondej, 2016; Mahasneh \& Al-Alwan, 2011; Moreno,
González-Cutre, Sicilia, \& Spray, 2010). Furthermore, the current study's findings indicated that epistemological beliefs were not significantly associated with intrinsic motivation. This result verified the hypothesis that epistemological beliefs and intrinsic motivation have no substantial association with each other. The review of the past literature indicated that there is a lack of research regarding the association between epistemological beliefs and motivation. The present study's outcome is by Hofer's (1994) study results. He concluded that learners' intrinsic motivation was substantially associated with their beliefs related to mathematics.

The results of the t-test found that females were more intrinsically motivated than males which is consistent with the past studies that reported girls revealed greater intrinsic motivation (Martin, 2009). In terms of prediction, goal orientation accounted for a $35 \%$ variance in intrinsic motivation which is consistent with the previous literature where learners having a high goal orientation were successful in terms of their elevated competencies (e.g., Dweck \& Leggett, 2000). In other words, learning aims augment the intrinsic motivation which in turn facilitates learners' learning progress. In an educational environment, numerous activities present an opportunity to gather new knowledge. Therefore, learners having strong goal orientation have numerous opportunities to acquire their main goal and to enhance their competence which consequently facilitates their intrinsic motivation (Ryan \& Deci, 2000a). In the end, it can be concluded from previous literature and the current study's findings that goal orientation augments intrinsic motivation among the learners.

In contrast, epistemological beliefs have not predicted intrinsic motivation, as highlighted by Buehl and Alexander (2005) in his study due to the reason that the learners who held more simple epistemological beliefs were subjected to lower competency beliefs. Paulsen and Feldman (1999) revealed that learners' beliefs regarding simplicity of knowledge were negatively associated with their intrinsic motivation and self-efficacy. The aforementioned studies reveal a uniform pattern where naïve epistemological beliefs decreased learners' intrinsic motivation

The current study's results endorse the findings of past literature that the learners must hold goal orientation perceptions. Teachers might facilitate learners to embrace goal orientation to amplify their intrinsic motivation. Besides, they might assist learners in achieving educational accomplishments. This study emphasized that goal orientation impacted intrinsic motivation positively. This finding advocated that endorsing goal orientation can prove to be a crucial aspect in augmenting learners' motivation and engagement in their learning tasks. Moreover, the current study's findings could help the language instructors in understanding the way their pupils reflect upon learning and knowledge which in turn help 
them in dealing with their pupils effectively. To produce engineers with extraordinary technical skills, the current study lays stress on intrinsic motivation regarding their learning and teaching methods. The present study's findings would help teachers to utilize effective teaching methodologies to upsurge engineering students' motivation related to technical skills. Additionally, educationalists ought to present learning tasks fascinatingly and entertainingly, as well as assist learners to set ideal and practical goals to raise their intrinsic motivation levels. Moreover, parents ought to consider the impact of their children's goal orientation as one of the crucial factors in the origination of an elevated degree of intrinsic motivation. Lastly, the learners ought to foster their capabilities in such a way that they set their goal orientations, and adjust to varied motivational situations, for educational learning through their university stage.

\section{REFERENCES}

[1] Afzal, H., Ali, I., Khan, M. A., \& Hamid, K. (2010). A study of university students' motivation and its relationship with their academic performance. International Journal of Business and Management, 5(4), p80.

[2] Ahmed, S. (2009). Methods in sample surveys. Dept. of Biostatistics School of Hygiene and Public Health Johns Hopkins University.

[3] Alias, M., Lashari, T. A., Akasah, Z. A., \& Kesot, M. J. (2014). Translating theory into practice: integrating the affective and cognitive learning dimensions for effective instruction in engineering education. European Journal of Engineering Education, 39(2), 212-232.

[4] Ames, C. (1992). Classrooms: Goals, structures, and student motivation. Journal of Educational Psychology, 84(3), 261-271.

[5] Asif, M. (2011). Achievement goals and intrinsic motivation: A case of IIUM. International Journal of Humanities and Social Science, 1(6), 196-206.

[6] Benlahcene, A., Lashari, S. A., \& Lashari, T. A. (2017). Goal-orientation, epistemological beliefs towards intrinsic motivation among engineering students: A review. In IOP Conference Series: Materials Science and Engineering (Vol. 226, No. 1, p. 012192). IOP Publishing.

[7] Bidin, S., Jusoff, K., Aziz, N. A., Salleh, M. M., \& Tajudin, T. (2009). Motivation and attitude in learning English among UiTM students in the northern region of Malaysia. English Language Teaching, 2(2), p16.

[8] Buehl, M. M., \& Alexander, P. A. (2005). Motivation and performance differences in students' domain-specific epistemological belief profiles. American Educational Research Journal, 42(4), 697-726.

[9] Cerasoli, C. P., \& Ford, M. T. (2014). Intrinsic motivation, performance, and the mediating role of mastery goal orientation: A test of self-determination theory. The Journal of psychology, 148(3), 267-286.

[10] Chen, J. A., \& Pajares, F. (2010). Implicit theories of ability of Grade 6 science students: Relation to epistemological beliefs and academic motivation and achievement in science. Contemporary educational psychology, 35(1), 75-87.

[11] Deci, E., \& Ryan, R (1985). Intrinsic motivation and self-determination in human behavior. New York: Plenum.

[12] Del Rosario, R. M., \& Bernardo, A. B. (2012). Personal epistemologies and motivation in schools: The relationship between students' epistemological beliefs and intrinsic motivation in learning. Soonchunhyang Journal of Humanities, 31, 277-307.

[13] Dweck, C. S., \& Leggett, E. L. (2000). A social-cognitive approach to motivation and personality.

[14] Elliot, A. J., Faler, J., McGregor, H. A., Campbell, W. K., Sedikides, C., \& Harackiewicz, J. M. (2000). Competence valuation as a strategic intrinsic motivation process. Personality and Social Psychology Bulletin, 26(7), 780-794.

[15] Elliot, A. J., Murayama, K., \& Pekrun, R. (2011). A 3× 2 achievement goal model. Journal of Educational Psychology, 103(3), 632-648.

[16] Esa, A., Padi, S., \& Hassan, S. S. S. (2015). Employability Skills in Engineering Programs: A Case Study in Malaysian Polytechnics. Advanced Science Letters, 21(7), 2442-2445.

[17] Froiland, J. M., Oros, E., Smith, L., \& Hirchert, T. (2012). Intrinsic motivation to learn: The nexus between psychological health and academic success. Contemporary School Psychology: Formerly" The California School Psychologist", 16(1), 91-100.

[18] Gao, Z., Podlog, L. W., \& Harrison, L. (2012). College students' goal orientations, situational motivation, and effort/persistence in physical activity classes. Journal of Teaching in Physical Education, 31(3), 246-260.

[19] Gottfried, Marcoulides, G. A., Gottfried, A. W., \& Oliver, P. H. (2009). A latent curve model of parental motivational practices and developmental decline in math and science academic intrinsic motivation. Journal of educational psychology, 101(3), 729.

[20] Goudas, M., Biddle, S., \& Fox, K. (1994). Achievement goal orientations and intrinsic motivation in physical fitness testing with children. Pediatric Exercise Science, 6, 159-159.

[21] Grainger, M. K. C. a. P. (2014). The effect of epistemological beliefs on teaching-learning conceptions of pre-service teachers of religion. Global Journal of Teacher Education, ISSN: 2366-6392 Vol. 2 (3), pp. 176-184,

[22] Hair, J. F. J., Money, A. H., Samouel, P. \& Page, M. (2007). Research methods for business. United States of America: John Wiley \& Sons.

[23] Heintz Jr, P., \& Steele-Johnson, D. (2004). Clarifying the conceptual definitions of goal orientation dimensions: Competence, control, and evaluation. Organizational Analysis, 12(1), 5-19.

[24] Heiskanen, H., \& Lonka, K. (2012). Are epistemological beliefs and motivational strategies related to study 
engagement in higher education. Procedia-Social and Behavioral Sciences, 69, 306-313.

[25] Hernandez, P. R., Bodin, R., Elliott, J. W., Ibrahim, B., Rambo-Hernandez, K. E., Chen, T. W., \& de Miranda, M. A. (2014). Connecting the STEM dots: measuring the effect of an integrated engineering design intervention. International journal of Technology and design Education, 24(1), 107-120.

[26] Hofer, B. K. (1994). Epistemological Beliefs and First-Year College Students: Motivation and Cognition in Different Instructional Contexts.

[27] Hofer, B. K. (2001). Personal epistemology research: Implications for learning and teaching. Educational Psychology Review, 13(4), 353-383.

[28] Hofer, B. K. (2004). Introduction: Paradigmatic approaches to personal epistemology. Educational Psychologist, 39 (1), $1-3$

[29] Hofer, B. K., \& Pintrich, P. R. (2004). Personal epistemology: The psychology of beliefs about knowledge and knowing: Psychology Press.

[30] Ibrahim, B., DeMiranda, M. A., Lashari, T. A., \& Siller, T. J. (2017). Teamwork and Engineering Design Outcomes: Examining the Relationship among Engineering Undergraduate Students. In 2017 7th World Engineering Education Forum (WEEF) (pp. 628-635). IEEE.

[31] Jnr, H. J. F., Money, A. H., Samouel, P., \& Page, M. (2007). Research Methods for Business, UK Edition. John Wiley and Sons Ltd, West Sussex England.

[32] Karakolidis, A., Pitsia, V., \& Emvalotis, A. (2019). The case of high motivation and low achievement in science: what is the role of students' epistemic beliefs? International Journal of Science Education, 41(11), 1457-1474.

[33] Karatas, H., \& Erden, M. (2017). Predictors of Academic Motivation: Epistemological Beliefs, Learning Approaches, and Problem Solving Skills. International Online Journal of Educational Sciences, 9(4), 897-916.

[34] Kenny, M. (2013). The promise of work as a component of educational reform. The Oxford handbook of the psychology of working, 273-291.

[35] Lai, P. Y. M., Chan, K. W., \& Wong, K. Y. A. (2006). A study of intrinsic motivation, achievement goals, and study strategies of Hong Kong Chinese secondary students.

[36] Legault, L. (2017). Self-Determination Theory. In V. Z.-H. a. T. Shackelford (Ed.), Encyclopedia of Personality and Individual Differences (pp. 1-9). New York: Springer.

[37] Lerdpornkulrat, T., Koul, R., \& Poondej, C. (2016). Relationship between perceptions of classroom climate and institutional goal structures and student motivation, engagement, and intention to persist in college. Journal of Further and Higher Education, 42(1), 1-14.

[38] Linnenbrink, E. A., \& Pintrich, P. R. (2002). Achievement goal theory and affect: An asymmetrical bidirectional model. Educational Psychologist, 37(2), 69-78.

[39] Mahasneh, R. A., \& Al-Alwan, A. F. (2011). Goal Orientation of university students and its relationship to Self-Efficacy and Intrinsic Motivation. Journal of
Institutional Research Journal of Institutional Research South East Asia South East Asia, 9(2), 21.

[40] Maralani, F. M. (2016). The Mediation Role of Intrinsic and Extrinsic Motivation in the Relationship between Creative Educational Environment and Metacognitive Self-Regulation. Journal of Education and Learning, 5(3), 272-277.

[41] Martin, A. J. (2009). Motivation and engagement across the academic life span: A developmental construct validity study of elementary school, high school, and university/college students. Educational and Psychological Measurement, 69(5), 794-824.

[42] Mason, L., Gava, M., \& Boldrin, A. (2008). On warm conceptual change: The interplay of text, epistemological beliefs, and topic interest. Journal of educational psychology, $100(2), 291$

[43] McCollum, D. L., \& Kajs, L. T. (2007). Applying Goal Orientation Theory in an Exploration of Student Motivations in the Domain of Educational Leadership. Educational Research Quarterly, 31(1), 45-59.

[44] Moreno, J. A., González-Cutre, D., Sicilia, Á., \& Spray, C. M. (2010). Motivation in the exercise setting: Integrating constructs from the approach-avoidance achievement goal framework and self-determination theory. Psychology of Sport and Exercise, 11(6), 542-550.

[45] Orsini, C. A., Binnie, V. I., \& Tricio, J. A. (2018) Motivational profiles and their relationships with basic psychological needs, academic performance, study strategies, self-esteem, and vitality in dental students in Chile. Journal of Educational Evaluation for Health Professions, 15(11), 1-6. doi: 10.3352/jeehp.2018.15.11

[46] Osborne, J. W., \& Overbay, A. (2004). The power of outliers (and why researchers should always check for them). Practical assessment, research \& evaluation, 9(6), 1-12.

[47] Oschatz, K. (2015). Epistemological beliefs and motivation. In J. D. Wright (Ed.), International encyclopedia of the social \& behavioral sciences (2nd ed., pp. 887-893). Oxford: Elsevier.

[48] Paulsen, M. B., \& Feldman, K. A. (1999). Student motivation and epistemological beliefs. New Directions for Teaching and Learning, 1999(78), 17-25.

[49] Pintrich, P. R. (2000). An achievement goal theory perspective on issues in motivation terminology, theory, and research. Contemporary educational psychology, 25(1), 92-104.

[50] Pintrich, P. R., \& Schunk, D. H. (2002). Motivation in education: Theory, research, and applications: Prentice Hall.

[51] Reeve, J. (2012). A self-determination theory perspective on student engagement. In A. L. R. S. L. Christenson, \& C. Wylie (Ed.), Handbook of research on student engagement (pp. 149-172). New York, NY, US: Springer.

[52] Ryan, R. M., \& Deci, E. L. (2000a). Intrinsic and extrinsic motivations: Classic definitions and new directions. Contemporary educational psychology, 25(1), 54-67.

[53] Ryan, R. M., \& Deci, E. L. (2000b). Self-determination theory and the facilitation of intrinsic motivation, social 
692 The Role of Goal Orientation and Epistemological Beliefs in Intrinsic Motivation among International Engineering Students

development, and well-being. American psychologist, 55(1), 68-78.

[54] Saari, P. (2012). Intrinsic Motivation: Psychological and Neuroscientific Perspectives.

[55] Schommer-Aikins, M. (2004). Explaining the epistemological belief system: Introducing the embedded systemic model and coordinated research approach. Educational Psychologist, 39(1), 19-29.

[56] Sekaran, U. (2010). Research Methods for Business: A Skill Building Approach Singapore: John Willey dan Sonc. Inc.

[57] Şen, Yilmaz, \& Yurdugul. (2014). An Evaluation of the Pattern between Students' Motivation, Learning Strategies, and Their Epistemological Beliefs: The Mediator Role of Motivation. Science Education International, 24(3), 312-331.

[58] Shehzad, M. W., Lashari, S. A., Alghorbany, A., \& Lashari, T. A. (2019). Self-efficacy Sources and Reading Comprehension: The Mediating Role of Reading Self-efficacy Beliefs. 3L: Language, Linguistics, Literature: The Southeast Asian Journal of English Language Studies, 25(3): $90-105$
[59] Shernoff, D. J., \& Csikszentmihalyi, M. (2009). Cultivating engaged learners and optimal learning environments. Handbook of positive psychology in schools, 131-145.

[60] Tabachnick, B. G., \& Fidell, L. S. (2007). Using multivariate statistics. Allyn \& Bacon/Pearson Education.

[61] Turner, J. R. (2013). Cross-Sectional Study. Encyclopedia of Behavioral Medicine, 522-522.

[62] Vansteenkiste, M., Timmermans, T., Lens, W., Soenens, B., \& Van den Broeck, A. (2008). Does extrinsic goal framing enhance extrinsic goal-oriented individuals' learning and performance? An experimental test of the match perspective versus self-determination theory. Journal of Educational Psychology, 100(2), 387-397.

[63] Vatankhah, M., \& Tanbakooei, N. (2014). The Role of Social Support on Intrinsic and Extrinsic Motivation among Iranian EFL Learners. Procedia-Social and Behavioral Sciences, 98, 1912-1918.

[64] Zubairi, A. M., \& Sarudin, I. (2009). Motivation to learn a foreign language in Malaysia. GEMA Online Journal of Language Studies, 9(2), 73-87. 